\title{
APROXIMACIÓN A LA ESTRUCTURA ESPACIAL DE LAS TRANSACCIONES DE DERIVADOS FINANCIEROS EN EL MERCADO EXTRABURSÁTIL OTC
}

\author{
Juan Carlos Fernández Cela \\ Profesor Asociado de la Universidad Complutense de Madrid. Departamento de Historia, Teorías y Geografía Políticas \\ juancarlosfernandezcela@yahoo.es \\ ORCID iD: https://orcid.org/0000-0001-6131-6103
}

Recibido: 10/02/2020; Aceptado: 12/04/2021. Publicado: 30/06/2021

Cómo citar este artículo/citation: Fernández Cela, Juan Carlos (2021). Aproximación a la estructura espacial de las transacciones
de derivados financieros en el mercado extrabursátil OTC. Estudios Geográficos, 82 (290), e066. https://doi.org/10.3989/ estgeogr.202077.078

RESUMEN: Con este trabajo se pretende determinar algunos rasgos de la red espacial de relaciones financieras internacionales del mercado de derivados de venta libre -over the counter-. Se ha reconstruido su estructura territorial a través de la Encuesta Trienal 2019 de Mercados Globales de Derivados del Banco de Pagos Internacionales, que ofrece información desagregada por Estados y divisas en los contratos firmados, lo que hace posible establecer las principales características de este mercado financiero.

Se detecta una elevada concentración de los contratos suscritos en los centros financieros de Reino Unido y Estados Unidos, y con Hong Kong como tercer mercado emergente. Los datos de los últimos años revelan que Reino Unido ha triplicado el valor de este mercado desde el referéndum del Brexit de 2016, lo que pone de relieve su solvencia internacional como mercado financiero de referencia, y que la salida de la UE no está perjudicando su posición global.

Existen diversos factores de localización de los fondos de cobertura -hedge funds-: un entorno regulatorio anglosajón, diferencias entre Estados en las condiciones de garantías legales, información asimétrica, o el desarrollo de las técnicas de pastoreo son algunas condiciones que determinan la localización y morfología de los flujos de capital. La investigación de la estructura espacial de la red financiera mundial puede mejorar el conocimiento del proceso de contagio entre territorios, e introducir medidas paliativas ligadas a un mayor control del marco regulador de los flujos financieros globales.

PALABRAS CLAVE: Geografía financiera; mercado de derivados; flujos de capital; geoeconomía; contagio financiero; paraísos fiscales; regulación financiera; unidad de inteligencia financiera.

\section{APPROXIMATION TO THE SPATIAL STRUCTURE OF FINANCIAL DERIVATIVE TRANSACTIONS IN THE OTC OVER-THE-COUNTER MARKET}

ABSTRACT: This paper aims to identify some features of the spatial network of international financial relations in the over-the-counter derivatives market. Its territorial structure has been reconstructed through the 2019 Triennial Survey of Global Derivatives Markets of the Bank for International Settlements, which provides information disaggregated by states and currencies in the contracts signed, making it possible to establish the main characteristics of this financial market.

There is a high concentration of contracts signed in the financial centres of the United Kingdom and the United States, with Hong Kong as the third emerging market. Data from recent years reveal that the UK has tripled the value of this market since the Brexit referendum in 2016, highlighting its international solvency as a financial market of reference, and that the exit from the EU is not harming its global position.

There are several factors that determine the location of hedge funds: an Anglo-Saxon regulatory environment, differences between states in the conditions of legal guarantees, asymmetric information, and the development of herding techniques are some of the conditions that determine the location and morphology of capital flows. Research into the spatial structure of the global financial network can improve knowledge of the process of contagion between territories, and introduce mitigating measures linked to greater control of the regulatory framework of global financial flows.

KEY WORDS: Financial geography; over the counter; capital flows; geoeconomics; financial contagion; swaps; regulation; financial location. 


\section{INTRODUCCIÓN}

A pesar de su juventud, la disciplina de la geografía financiera está teniendo una amplia acogida y aceptación en un espacio de investigación académica que, a raíz de la crisis de 2007-2008, ha prestado mayor atención a las cuestiones de financiarización y la morfología de los flujos financieros internacionales (Clark, 2006; Aalbers, 2015; 2016).

Existe así un especial interés en conocer con detalle la arquitectura espacial de los movimientos internacionales de capital. Su morfología, tal y como la conocemos en la actualidad, procede de su fase de expansión a comienzos de la Segunda Revolución Industrial. Hobson (1902) sería uno de los primeros en interesarse por la cuestión de la formación del imperialismo y la inversión de excedentes monetarios de espacios centrales en los periféricos. Sin embargo, no será hasta ya iniciados los años setenta con estudios sobre la exclusión financiera de los distritos urbanos (Harvey, 1974) o de los mercados hipotecarios (Boddy, 1976), cuando comienza a aparecer una especialización en diferentes subdisciplinas dentro de este campo. Su maduración como rama independiente procede de una diversificación en los contenidos de estudio, que van desde la reproducción espacial de desigualdades a partir de la red financiera global (Sokol, 2013), su morfología espacial (Clark, 2017) o el campo de la financiarización de la vivienda (Méndez, 2020).

Una de las líneas de investigación más prometedora es el análisis de los factores de localización y la lógica que determina el comportamiento de los flujos espaciales de capital financiero (Méndez, 2019). Conocer estos patrones permite identificar no solo la cartografía del capital, sino conocer el funcionamiento interno de estos sofisticados y volátiles productos. Reconstruir el procedimiento de contagio espacial de riesgo sistémico, es clave para delimitar la expansión territorial de las crisis económicas, y establecer por los reguladores una red de alerta temprana más eficaz en este tipo de situaciones. Con este trabajo se pretende aportar información sobre la estructura espacial del mercado de derivados en mercados extrabursátiles -over the counter-, uno de los más complejos, opacos y con mayor impacto en el sistema financiero internacional. ${ }^{1} \mathrm{~A}$ pesar de su protagonismo en la crisis de 2007-2008, tiene una red de relaciones espaciales poco conocidas más allá de los estudios elaborados por economistas. La escasez de análisis por otras disciplinas es debido a la existencia de un entramado societario intencionadamente complejo de estudio, especialmente en los mercados extrabursátiles. Su es- tudio ha quedado así circunscrito casi exclusivamente a un reducido número de expertos en finanzas, y ello a pesar de su considerable impacto social y político. Perfilar desde una perspectiva geográfica algunos rasgos sobre su funcionamiento y organización, puede ayudar a entender los canales espaciales de contagio y la estructura nodal de la red entre centros financieros y los países donde se referencian sus operaciones.

\section{FUENTES Y METODOLOGÍA}

La metodología empleada se encuentra limitada por las escasas fuentes de información de acceso público. Existe la obligatoriedad de presentar cualquier contrato de derivados en cualquiera de los seis grandes registros de operaciones existentes en la actualidad. Todos ellos están habilitados para inscribir cualquier tipo, excepto el ICE Trade Vault Europe Ltd., que se limita a derivados con subyacentes en materias primas, acciones, tipos de interés y créditos. Estos registros no son de sencillo acceso, aunque constituyen una extraordinaria fuente de investigación, ya que están constantemente actualizadas y conservan un valioso histórico que permitiría analizar las cadenas espaciales en diferentes ciclos económicos. Sin duda se podría reconstruir con mayor precisión las redes internacionales de derivados con esta información, una vía que podría explorarse en futuros trabajos para aquellos interesados en estas cuestiones.

La regulación de la UE sobre el depósito y el cálculo de operaciones de derivados se contempla en el Reglamento (UE) n.o 648/2012 del Parlamento Europeo y del Consejo, de 4 de julio de 2012, relativo a los derivados extrabursátiles, las entidades de contrapartida central y los registros de operaciones (ESMA, 2019). En él se establece el cálculo de posiciones por el registro de operaciones en virtud del reglamento EMIR, y puede ser una fuente de información complementaria importante, especialmente para evaluar la evolución histórica de las principales magnitudes.

Los datos analizados corresponden íntegramente a la Encuesta Trianual del BPI (op cit. 2019), procedente de la información aportada por los principales bancos de 53 países. A pesar de no estar diseñada para la elaboración de estudios espaciales, constituye que es una herramienta eficaz para la reconstrucción de algunos rasgos básicos de la red territorial del mercado de derivados y divisas en mercados OTC. Asimismo, permite determinar las relaciones entre el valor de la divisa expresada en el principal nocional de los contratos declarados por las entidades bancarias informantes, y la localización de los centros financieros 
gestores, su capacidad de atracción y el espacio de influencia geoeconómico de referencia.

\section{ESTADO DE LA CUESTIÓN}

El mercado de derivado no es un invento de reciente creación. Aunque sus primeras referencias corresponden a intercambios de grano y esclavos en Mesopotamia (Fisanotti, 2014), su morfología actual no surge hasta las postrimerías del s. XIX, en torno a la comercialización de productos agrícolas en la bolsa de Chicago, que se ha convertido en referente mundial a través del Chicago Mercantile Exchange (CME), y posteriormente se extendió por etapas al mercado de Nueva York, Londres y al resto del mundo (Muellerleile 2015, p. 1805).

A pesar de las múltiples innovaciones técnicas introducidas, que han provocado una diversificación de productos, su estructura de funcionamiento no ha cambiado sustancialmente desde su expansión favorecida por la consolidación de las políticas neoliberales de los años 80. Un punto de inflexión es la derogación en 1999 de la Ley Glass-Steagall, que impedía la fusión de la banca comercial y de inversión. Un año más tarde, la administración Clinton facilitó la desregulación de los mercados con la Ley de Modernización de Futuros de Materias Primas, que permitió el desarrollo de los productos subprime para hipotecas, al mismo tiempo que facilita la financiarización de productos básicos. La convergencia de ambas medidas legales facilitó una expansión exponencial incontrolada que, según algunos especialistas (Crotty, 2009), está tras el origen del colapso financiero de 2008 y la traumática crisis posterior.

Sin embargo, no todos piensan así. Barth y Landsman (2010) exculpan a los gestores de activos porque la información financiera que manejan tiene un carácter individual, no está diseñada para tomar decisiones conjuntas, es insuficiente y confusa. Sus operaciones obedecen a una lógica puntual de movimientos especulativos y no tienen por qué representar tendencias globales. Traslada la responsabilidad a los reguladores contables, que sí están obligados a conocer los riesgos inherentes al mercado de derivados. Serían en este caso la Financial Accounting Standards Board (FASB) para el mercado estadounidense, y el International Accounting Standards Board (IASB) como regulador internacional, los responsables últimos de las presiones especulativas de los derivados sobre el resto del mercado. Las diferencias entre las normas contables estadounidenses e internacionales puede dificultar la claridad de determinadas operaciones entre Estados y acelerar la propagación del contagio espacial en caso de crisis sistémica. Kalinowski (2011) va más allá justificando la desregulación, ya que mayores controles suponen un incremento de los costes de transacción. La crítica se extiende a los reguladores que "...quieren restringir la libertad y aumentar la transparencia del mercado. Estas instituciones deben tener en cuenta las características básicas de los instrumentos derivados y las consecuencias de los cambios en la regulación del mercado para las empresas no financieras".

La reacción a la ola de liberalización del mercado de derivados se materializa con la Ley Dodd-Frank, promovida por la administración Obama en 2010, que ha intentado regular su funcionamiento. Tal vez su reforma más sustancial es la desviación de la negociación de permutas financieras -swaps- contratadas desde el mercado libre de OTC, hacia las cámaras de compensación de los mercados regulados, sujetos a condiciones prefijadas con un menor riesgo en su ejecución. Estos productos son una pieza clave en la negociación de hipotecas a largo plazo, en la medida en que la permuta permite a los bancos protegerse ante la eventualidad de un interés superior durante distintos períodos de vida del crédito hipotecario. Un marco de mayor control financiero modifica la red espacial de derivados, ya que operaciones reguladas pasan obligatoriamente por mercados bursátiles conocidos y localizados. Por el contrario, las operaciones individuales OTC facilitan la dispersión geográfica de los flujos financieros, que puede determinarse libremente en el contrato firmado entre el gestor y su contraparte, pudiendo favorecer la presencia sobredimensionada de permutas, con el peligro de reproducir una situación similar a la de 2008 (Algieri, 2018).

Este retorno a prácticas neoliberales está ligado a las presiones políticas de la International Swaps and Derivatives Association (ISDA), que están consiguiendo lo que ellos denominan como una "regulación diluida" de los ya de por sí escasos procedimientos de control y seguimiento de operaciones, aprobados en su mayor parte durante la administración Obama. La presión de este lobby afecta especialmente a la Ley Dodd-Frank, que ha sido derogada en su mayor parte por Trump en 2018, y especialmente la Regla Volcker, que impide a los bancos realizar determinadas operaciones especulativas de riesgo para sus clientes. Esta contrarreforma permite liberar reservas obligadas de efectivo por valor de 40000 millones de dólares de los bancos americanos, que van directamente a incrementar el valor de las operaciones del mercado de derivados, con el consiguiente peligro de repetir la situa- 
ción previa al colapso financiero de 2007 (Schroeder, 2019). La situación actual de pandemia global por el COVID-19 está provocando una nueva incertidumbre en los mercados financieros internacionales, que sin duda va a afectar a las decisiones políticas de la administración Biden sobre la negociación de derivados en una batalla que está lejos de concluir.

Uno de los primeros estudios de referencia sobre la estructura espacial de este mercado es el de Agnes (2000), donde ya anticipaba antes de la crisis de 2008, que la morfología de los servicios financieros globales no conlleva "el fin de la geografía", tal como titula su propio estudio. Lejos de ello, y basándose en estudios cualitativos del comportamiento de las permutas financieras en Australia, se detecta una estructura espacial en los sistemas de relación entre operadores globales e inversores locales, que tienen a menudo intereses opuestos. La estructura nodal de intercambios ente ambas escalas permite identificar y reconstruir los mecanismos del mercado de estos contratos desde los centros financieros internacionales hacia mercados regionales y locales: "La industria de permutas globales comprende una red internacional de operaciones altamente localizadas pero interconectadas basadas en centros financieros mundiales" (p. 347).

Diferencias entre reguladores son claves para comprender sus factores de localización. Houston, Lin y Ma (2012, p. 1845) destacan que los grandes operadores de derivados deslocalizan su actividad según el tipo de regulación vigente en cada jurisdicción. Existen factores de atracción y expulsión -push and pull-, que facilitan el desplazamiento de operaciones financieras entre distintos territorios. Los bancos y otros establecimientos financieros transfieren capital y operaciones a espacios con entornos institucionales menos regulados, y luego confían las disputas a los arbitrajes financieros, una herramienta que no está diseñada para armonizar diferentes modelos regulatorios. Sin embargo, no basta con tener una regulación laxa para captar capitales, es necesario además ser un país desarrollado, acreedor y contar con unas instituciones sólidas y garantistas en cuanto a los derechos de propiedad. Esto podría explicar que grandes economías como Estados Unidos o Reino Unido, que comparten el modelo de regulación jurisdiccional anglosajón, sea el preferido en operaciones financieras internacionales, y por tanto los flujos financieros se concentren en estos países. La deslocalización en la cadena espacial de gestión del producto financiero se encuentra limitada geográficamente a aquellos Estados que aceptan este marco regulatorio, donde se garantiza un cum- plimiento de las condiciones contractuales. Costes judiciales, garantías legales y rapidez en la ejecución de sentencias son factores que discriminan la localización de los contratos de derivados. Es más rápido y barato pleitear en Reino Unido o Países Bajos que en Estados Unidos, Francia o España. La elección de una jurisdicción depende en última instancia del acuerdo entre las partes que suscriben el contrato de futuros, permutas financieras u opciones. Ambos buscan un entorno legal lo más adecuado posible a sus intereses en caso de demanda. Si un swap se ejecuta en Nueva York al amparo de un subyacente de Colombia, es más factible que las partes se sometan a procedimiento arbitral o judicial en Estados Unidos.

Gandré, Mariathasan, Merrouche y Ongena (2020, p. 3) han estudiado los efectos de las reformas en la regulación del mercado de derivados introducidos por el G20. Coinciden con D'Avino (2017) en señalar que la deslocalización espacial a jurisdicciones con menor capacidad de regulación puede generar un efecto perverso en los espacios, tanto en origen como en destino. "Se mueven a las jurisdicciones que están menos preparadas para la supervisión-de los mercados de derivados-y los bancos compensan las posiciones que no pueden moverse con alternativas de riesgo aún mayor". Incluso desde despachos de abogados donde se diseñan las operaciones internacionales de los contratos, califican la eficacia de las reformas del G20 como "limitadas" (Uría Menéndez, 2019, p. 7).

Una desigual capacidad de adaptación legislativa en la reforma de los mercados financieros, está permitiendo a los grandes operadores de derivados globales desplazar sus operaciones de mayor riesgo a estos territorios. Calidad diferencial de las instituciones, imposibilidad práctica de ejecución de sanciones y buen gobierno, son aspectos ligados al ejercicio efectivo de control de los mercados de derivados. Lo mismo sucede con los costes de transacción de las operaciones entre mercados territoriales, encareciendo los contratos. Gandré et al. (2020) han identificado los flujos espaciales entre cinco grandes gestores de activos globales Bank of America, Citigroup, Goldman Sachs, JP Morgan y Morgan Stanley- en sus operaciones en IRS y FOREX ${ }^{2}$. La evolución de las interacciones entre sede social y filiales se manifiesta a través de un índice -Derivreg Index- que refleja diferencias en la capacidad regulatoria de los mercados por países. Identifica su eficacia como organizador y la red de relaciones entre sede central y delegaciones deslocalizadas en espacios financieros significativos. Japón, con un índice de nivel 5, es el más eficaz regulador de las operaciones de derivados, es- 
pecialmente de permutas financieras. Estados Unidos y Reino Unido se encuentran en un segundo nivel junto a Australia, México y Suiza. La UE está en un rango intermedio, mientras que Argentina, Corea del Sur o Turquía son los países con mayor exposición al riesgo por deficiencias o ausencias de controles.

Por otra parte, han podido determinar la proporción de participación de filiales extranjeras en los contratos gestionados por estos grandes operadores. Además de EE.UU., en el continente americano solo se ejecutan operaciones significativas deslocalizadas de permutas financieras en Argentina, Canadá y México. Proximidad geográfica, conocimiento del mercado y una posición estratégica, como es la de Argentina en el Cono Sur, parecen ser factores relacionados con esta decisión de determinar operaciones financieras en lugares determinados.

En Asia existe actividad significativa de permutas estadounidenses en China, Hong Kong, Singapur, Corea del Sur y Japón. Mientras en Europa, Reino Unido, Francia, Irlanda, Alemania, Rusia y Luxemburgo son los principales espacios de operación de derivados procedentes de EE. UU. No se han encontrado operadores relevantes en África, mientras que Australia tiene un mercado de participación destacado. Negociaciones de permutas deslocalizadas por encima de un $60 \%$ con respecto al valor total de su sede, solo se realizan en los centros financieros de máxima confianza: Londres y Tokio. México y Australia están en un rango intermedio que oscila entre el $10 \%$ y el $60 \%$. En la UE, Alemania ha disminuido su participación entre 2010 y 2015 en favor de Francia.

Los costes de transacción parecen ser otros factores de localización de las operaciones de derivados. Se ha entrevistado a varios expertos en la instrumentalización de este tipo de contratos, y coinciden en señalar que los cargos y comisiones de intermediación financiera son aspectos que los gestores consideran críticos en su decisión de ejecutar un contrato de derivado en un determinado país. Normalmente, los costes de gestión de un swap desde Londres son más baratos que desde otros centros financieros. La experiencia histórica de la City, una mayor competencia, junto con la complementariedad de otros servicios especializados permite rebajar la tarifa en operaciones complejas, que se ven beneficiadas por la economía de escala. ${ }^{3}$

Muellerleile (op. cit. 2015) destaca la importancia de un buen sistema de regulación para un comportamiento no especulativo del mercado de derivados. La reglamentación ha estado dirigida al control del sistema de precios con el objeto de garantizar la fluidez en el mercado, pero no está siendo suficiente para disminuir su volatilidad. La regulación comparti$\mathrm{da}$, que garantiza el cumplimiento de las condiciones en toda la cadena de intermediación, es un aspecto importante en la cartografía de relaciones financieras. No solo se trata solo de desarrollar productos en un marco regulatorio y fiscal favorable, sino de garantizar un ecosistema espacial diversificado donde la coordinación y correspondencia entre diferentes normativas garanticen las condiciones de inversión.

Otra dimensión de análisis territorial está subordinada a la gestión del riesgo y su interacción bidireccional entre mercados financieros y productivos. Al tratarse de operaciones basadas en la evolución de activos subyacentes, normalmente materias primas, tipos de interés, acciones o divisas entre otros, las cadenas espaciales de relaciones entre derivados y subyacentes son complejas e interdependientes. ${ }^{4} \mathrm{Su}$ interacción es bidireccional, los flujos se dirigen desde el territorio responsable del subyacente al mercado y viceversa. De este modo, una sequía en China y la consiguiente previsión de la disminución de producción de grano, va a afectar inmediatamente al mercado de derivados de materias primas en Chicago. Sin embargo, el efecto se produce también en sentido inverso. Modificaciones sustanciales en el valor de los mercados de derivados pueden inducir cambios estructurales en la economía y los territorios donde se localizan sus activos subyacentes. Esto fue lo que ocurrió en 2007, cuando el aumento en la demanda de derivados vinculados a biocombustibles encareció la distribución de cereal y oleaginosas para consumo humano, impactando con mayor severidad en los países más pobres. Marquina (2013, p. 149) señala que el nuevo modelo de financiarización de los mercados agrícolas ha desvirtuado el papel para el que está diseñado el mercado de futuros, repercutiendo a los consumidores de los Estados más pobres las consecuencias de la volatilidad de precios.

\section{FACTORES DE LOCALIZACIÓN DE LOS GESTORES DE DE- RIVADOS: EL CASO DE LOS FONDOS DE COBERTURA}

Existen cuatro dimensiones territoriales en la composición de los flujos espaciales de este mercado: primera, el marco jurídico donde se firma el contrato; segunda, localización del subyancente; tercera, mercados de colocación; y finalmente la ubicación de los tenedores.

Teo (2009) es un punto de referencia en la interpretación del comportamiento espacial de los fondos de cobertura. En su estudio del mercado asiático, aque- 
llos fondos que disponen de presencia física en el territorio, bien sea una oficina regional o algún tipo de representación, mejoran un $3,7 \%$ los rendimientos del capital con respecto a aquellos fondos que operan en territorios donde carecen de delegación, ya que les permite incrementar el cobro de comisiones y tarifas de sus operaciones. La ventaja comparativa que proporciona la deslocalización, viene canalizada por el dominio del idioma y la disponibilidad de información asimétrica como ventaja competitiva. Diferencias en la organización espacial de los fondos influyen en el alfa o diferencial entre rendimiento esperado y real. Los mercados emergentes se caracterizan por una asimetría de información mayor entre local y extranjera, incrementando los beneficios de estos productos en las regiones periféricas. Una estrategia de activos no deslocalizados es el intercambio de rendimientos de inversiones en sus respectivos lugares de influencia, con el objeto de mejorar el acceso al capital. La importancia del territorio sobre la calidad de estos productos es relevante hasta el punto de implementarlo en algunos modelos financieros que detectan los factores de rentabilidad como es el de Fung y Hsieh. ${ }^{5}$

Kellard, Millo, Simon y Engel (2017) señalan que el desarrollo de las técnicas de pastoreo entre fondos de inversión libre se relaciona con un entorno cultural de confianza compartido, donde un lenguaje común favorece una mayor interacción en las redes de conocimiento. Los estudios sobre las tendencias de localización de los fondos de cobertura son limitados, pero en su mayor parte y al igual que ocurre en otras redes de capital financiero, está muy presente el factor cultural. Zhang y Kim (2019) han detectado que la interacción entre valores sociales y lingüísticos son factores centrales que determinan los espacios de inversión desde grandes fondos soberanos de siete países de origen (China, Singapur, Corea, Noruega, Canadá, Qatar y Emiratos Árabes Unidos) a seis países de destino (Australia, Canadá, China, Alemania, Reino Unido y los Estados Unidos). Información asimétrica, percepción y evaluación del riesgo país, o fiabilidad en un marco regulatorio son componentes que determinan la elección de inversión. Lo mismo ocurre con otros estudios sobre las relaciones espaciales entre tenedores de activos y paraísos fiscales. En este caso, la estructura nodal de la red europea de los papeles de Panamá comparte una lógica similar al caso anterior, donde los restos del Imperio Británico y una herencia común de su historial colonial parecen jugar un papel central en la morfología de los flujos financieros entre Europa y sus espacios offshore de referencia cultural (Fernández Cela, 2019).
Bauer, Bonetti y Broeders (2018) han elaborado un análisis de econometría espacial sobre 191 fondos de pensiones de Países Bajos. Concluyen que existe una mayor tendencia al pastoreo cuando dos o más fondos comparten el mismo administrador, ya que la información común deriva en una planificación conjunta de inversiones sobre activos similares. Sin embargo, cuando el nexo común entre fondos no son gestores de activos sino fideicomisarios, las inversiones comunes descienden de manera significativa. Lo mismo sucede con la inversión en bienes raíces, donde no se identifica una tendencia tan acusada al pastoreo como en el caso anterior.

Es en este contexto donde Mihaljek y Packer (2010) consideran que este tipo de conductas condicionan la estabilidad financiera de los países, especialmente en espacios periféricos, sujetos a una mayor exposición a operadores que utilizan el mercado de derivados en prácticas con un elevado contenido especulativo. Esto se está percibiendo en el comportamiento de los mercados durante la pandemia de COVID-19, cuya propagación está causando correctivos en los mercados financieros de todo el planeta. En el caso español, grandes fondos de cobertura estadounidenses -Bridgewater, Citadel o AQR Capital- y británicos - Kite Lake, Marshall Wace- han elaborado una operación bajista conjunta valorada en 1.300 millones de euros sobre diversas empresas cotizadas en el IBEX35 como Santander, BBVA, Cellnex o Indra, obligando a la CNMV a suspender las posiciones cortas. Por su parte la European Securities and Markets Authority (ESMA), el organismo europeo que coordina a supervisores de mercados, rebaja la obligatoriedad de declarar aqueIlas posiciones bajistas que superen el $0,1 \%$ en vez del 0,5\% habitual. Estos fondos de inversión prevén, como consecuencia del estado de alarma por la pandemia por COVID-19, una caída en el valor de algunas empresas del selectivo español, lo que les permite obtener enormes beneficios en operaciones a la baja que aceleran la inestabilidad de empresas sistémicas españolas.

La CNMV (2006, p. 58) considera que regulación y fiscalidad son los principales factores de localización de los fondos de inversión libre. Una regulación inexistente o laxa constituye un factor favorable a este tipo de sociedades, que por su condición de alto riesgo y elevada diversificación y volatilidad de sus activos necesita entornos institucionales con bajos niveles de supervisión. A pesar de ello, los inversores consideran que la sujeción a una regulación incrementa su confianza, por lo que en ocasiones determinados fondos 
pueden deslocalizarse a países con mayores controles, si determinados inversores de gran tamaño reclaman esto como medida preventiva. La estructura y organización del activo está condicionada por la cobertura del memorando de entendimiento, que reduce las posibilidades de inversión a un número limitado de espacios geográficos. Las garantías de cumplimiento de los acuerdos internacionales en caso de conflicto es una cuestión básica, ya que facilitar la inversión en un Estado con elevada inestabilidad económica o geopolítica puede poner en peligro el cumplimiento de las condiciones contractuales.

Junto a estos factores, las diferencias fiscales entre Estados son claves a la hora de decidir la localización del gestor y de sus inversiones, que suelen pasar en ocasiones por paraísos fiscales para favorecer la elusión. La estructura y cargas fiscales de sociedades y personas, tanto para el propio fondo como para sus inversores, es determinante en la decisión de localización. También lo es la disponibilidad de personal cualificado, especialmente matemáticos e informáticos cualificados que diseñan los algoritmos y productos financieros. Siguiendo el ejemplo de otros casos como el de Luxemburgo, existe una especialización territorial en la localización de los fondos de cobertura en torno a las islas Caimán, que absorben un $60 \%$ del valor de todos los activos declarados. Se trata de una concentración extremadamente elevada con relación a su jurisdicción (Fichtner, 2016). La lógica organizativa no está tanto diseñada en captar fondos de procedencia ilícita u oscura, como ejercer de nudo en los sistemas de transferencias de grandes corporaciones globales, que eluden así el pago de impuestos y los sistemas regulatorios de las jurisdicciones onshore.

Los costes de deslocalización de los intermediarios financieros son comparativamente más bajos que otros sectores de actividad, especialmente la industria y sectores primarios, intensivos en infraestructuras y equipamientos. Esta ventaja favorece la diversificación espacial de funciones de los gestores de activos, que en el caso de los fondos de cobertura tienen una tendencia a instalarse en espacios offshore. A las conocidas ventajas fiscales y el anonimato que facilitan el desplazamiento de inversiones a paraísos fiscales, se contraponen algunos riesgos vinculados al retraso en la ejecución de órdenes de suscripción o la imposibilidad práctica de ejercitar derechos legales en determinados territorios donde la regulación no está garantizada. Agilidad en la tramitación de administrativa, requisitos de capital, existencia de medios y personal cualificado de soporte técnico, facilidad de contactos con clientes internacionales son otros factores que determinan su localización.

La concentración regional de clientes, que antes de la crisis financiera se consideraba un factor principal de localización (Duffie y $\mathrm{Hu}, 2008$ ), parece que ha perdido presencia por las condiciones favorables a inversiones deslocalizadas, por lo que no es ya tan importante la cercanía de las gestoras de activos, que en numerosos casos operan con inversores de numerosos países. Sinergias de uso compartido, impuestos a proveedores de servicios, protección al inversor, o eficiencia y estabilidad de los mercados son otras condiciones señaladas como importantes en esta decisión.

\section{RESULTADOS Y DISCUSIÓN}

\section{Estructura geoeconómica del mercado de derivados}

La crisis financiera no parece haber afectado al comportamiento estructural de operaciones de alto riesgo en el mercado de derivados, y aún es pronto para comprobar el impacto del COVID-19. Su evolución desde 2008 parece ser ajena a las múltiples críticas procedentes de sectores sociales, políticos, e incluso económicos sobre su funcionamiento e impacto negativo sobre el resto de la economía y la estabilidad financiera mundial. Lejos de disminuir, la evolución observada en los últimos años refleja un intenso crecimiento y consolidación en los principales centros financieros internacionales.

Los últimos resultados de la Encuesta Trienal de Mercados Globales de Derivados del Banco de Pagos Internacionales son elocuentes (BPI, 2019). Si en abril de 2016 la rotación diaria de derivados en el mercado OTC alcanzó el valor de 2,7 billones de dólares, en el mismo mes de 2019 se ha multiplicado por tres hasta alcanzar los 6,5 billones diarios (gráfico 1). Además, esta magnitud se ha multiplicado por trece desde 2001, lo que da idea del crecimiento exponencial de este tipo de operaciones en los mercados internacionales. Este fenómeno ha ido acompañado entre 1995 y 2019 de una intensa concentración espacial del mercado en torno a los grandes centros de Reino Unido y Estados Unidos, cuyos centros financieros absorben un $82,3 \%$ del comercio mundial, en detrimento de otros como Tokio, que ha perdido once puntos en este periodo, ocho en el caso de París o seis Singapur. Solo el mercado de Hong Kong ha hecho frente al predominio anglosajón al alcanzar un 5,9\% del mercado global con movimientos valorados en 435800 millones mientras que un tercer conjunto de países como Japón, Francia, Singapur, Australia y Canadá 
GRÁFICO 1

EVOLUCIÓN DE LA DISTRIBUCIÓN MUNDIAL DEL MERCADO DE DERIVADOS OTC (EN MILLONES DE DÓLARES, 1995-2019)

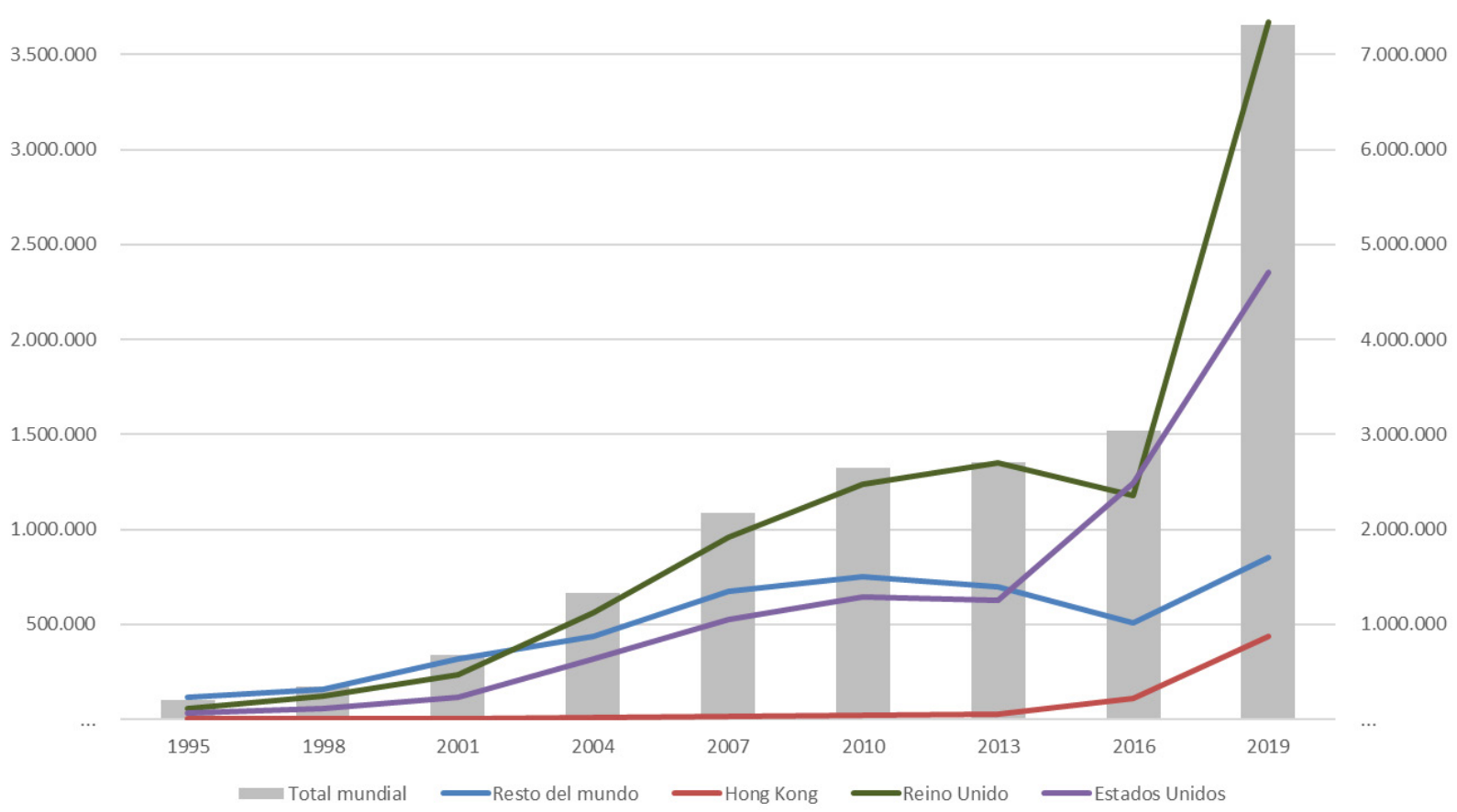

Fte.: BPI (2019) y elaboración propia.

GRÁFICO 2

DISTRIBUCIÓN MUNDIAL DE LA ROTACIÓN MENSUAL DEL MERCADO DE DERIVADOS (A ESCALA LOGARÍTMICA, EN MILES DE MILLONES DE DÓLARES, ABRIL DE 2019)

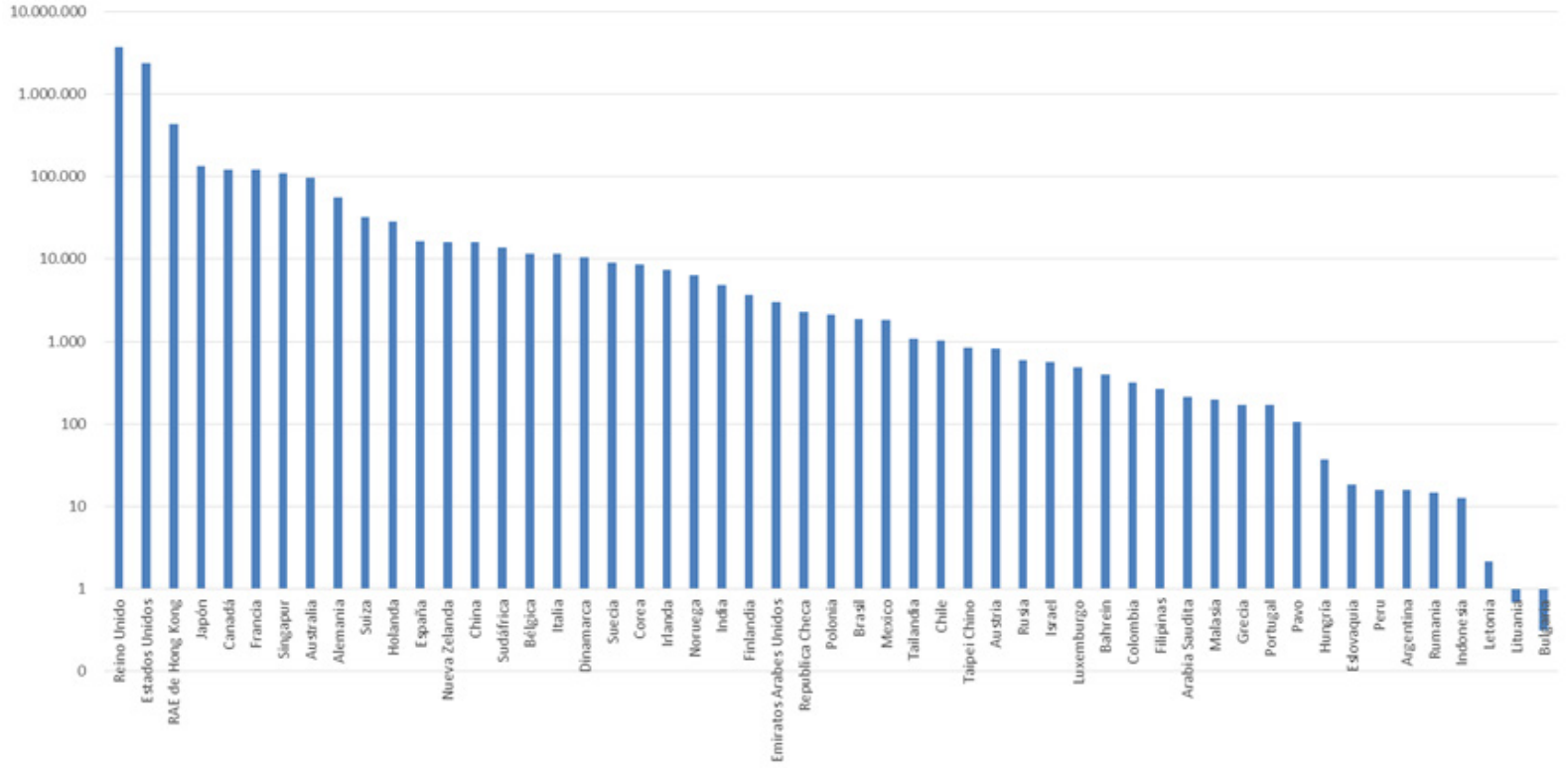

Fte.: BPI 2019 y elaboración propia. 
ejecutan operaciones en torno a los 100000 millones de dólares mensuales. La tendencia prolongada de concentración de estos instrumentos en Londres pone en cuestión algunos argumentos que dudan de su capacidad por seguir liderando el mercado mundial de derivados tras su salida de la UE (gráfico 2).

Lejos de producirse esta situación, se ha triplicado el valor de circulación de derivados en Reino Unido entre 2016, la fecha del referéndum de salida del Reino Unido de la UE y 2019. Esto pone de manifiesto que la reputación de Londres en los mercados financieros internacionales y la estructura política de las instituciones británicas son garantía suficiente para los inversores globales, que siguen confiando en su modelo organizativo, aunque esté fuera de la cobertura de la UE. Los intentos del BCE y de los gobiernos de Francia y Alemania de fortalecer los centros financieros de la Europa continental no parece tener de momento buenos resultados, al menos en estos productos, en la medida en que en ambos países la cuantía de las operaciones ha descendido ligeramente en el mismo período.

La evolución histórica hasta la crisis de 2008 revela que se ha producido una aceleración en los flujos transnacionales en detrimento de aquellos que operan exclusivamente en el mercado local. ${ }^{6} \mathrm{El}$ punto máximo alcanzado ocurrió en 2007, cuando la proporción de flujos transfronterizos sobre locales era del $66 \%$. Sin embargo, tras la crisis financiera se ha producido un punto de inflexión que ha provocado una pérdida de peso de los internacionales sobre los locales, a pesar de un contexto donde ambos indicadores han crecido exponencialmente. En 2019 su proporción ha descendido hasta el $51 \%$ en un contexto de retroceso global de la inversión exterior que no solo afecta a los derivados, sino a otros mercados importantes como la IED, y los mercados de bonos o deuda soberana, que están limitando el riesgo de diversificación espacial de inversiones en economías emergentes con alto riesgo de impago (Fernández Cela, 2015; 2015b).

EI BPI (op cit. 2019) establece tres tipologías diferentes de derivados: permutas financieras, futuros en mercados no organizados -forward rate agreement- $y$ opciones. Los primeros ya estuvieron detrás de algunas crisis financieras, como ha sucedió con la asiática de 1997 (Skinnera y Townend, 2002, p. 297). La mayor parte del crecimiento de derivados se explica por la participación de permutas, que representan un 63,7\% del conjunto global, y ello a pesar de las limitaciones que han impuesto algunas grandes economías globales como la UE, que desde 2011 ha prohibido sus operaciones más especulativas sobre riesgo de impago cuando el operador no es propietario del título -nacked CDS-.

Las permutas tienen elevada capacidad de externalización espacial hacia mercados internacionales. Un $67 \%$ del conjunto mundial comercializados en mercados extrabursátiles son transfronterizos, esto está ligado como veremos más adelante a una estrategia de diversificación territorial de activos de las grandes gestoras de fondos como estrategia básica de operaciones. Se diseña para su distribución en un mercado global en inversiones en múltiples países donde apenas un tercio se localizan en el mismo lugar de origen donde se gestionan los contratos.

A mucha distancia de este productos figuran los forward rate agreement, contratos de interés futuro a corto plazo donde el valor subyacente suele estar constituido por un depósito interbancario. Este conjunto representa un $29,2 \%$ del mercado mundial de derivados. El mercado de opciones de compra o venta constituye el tercer gran conjunto de derivados, apenas representan un $8 \%$ del mercado mundial. Existe por tanto un claro sesgo hacia el mercado de permutas, los productos con mayor apalancamiento y beneficios, pero que suponen un elevado riesgo de contagio sistémico.

El riesgo de contagio espacial es especialmente sensible en las estructuras organizativas de distribución de derivados entre territorios. Los grandes mercados de permutas adquieren productos sobre activos subyacentes deslocalizados en numerosas partes del mundo, a través de operaciones especulativas que causan peligrosos desequilibrios en algunos Estados financieramente vulnerables, que se ven afectados por contratos firmados a miles de kilómetros. El mercado de derivados en commodities -principalmente materias primas y energía- tiene un efecto mayor en países pobres, cuya menor renta intensifica el impacto social de una variación significativa de productos básicos de alimentación como es el caso del arroz o el cereal.

\section{Flujos espaciales en el mercado de divisas}

La divisa sobre la que se fija el contrato tiene un papel destacado en los movimientos transnacionales de capital. Constituye es un buen indicador de la estructura espacial de las carteras de activos en estos mercados, y permite obtener algunos resultados sobre su cartografía financiera. El carácter global de esos instrumentos tiene un reflejo en la diversificación de mo- 
nedas utilizadas, 39 en total. La divisa predominante es el dólar, que representa la mitad del valor total de movimientos diarios, seguido por el euro que supone un $24,4 \% .^{7}$ La importancia del dólar como moneda de referencia se ha consolidado en el mercado de derivados, ya que en 2004 representaba un tercio de los movimientos totales y en 2019 ha ascendido al 50\%. Las transacciones en euros han sido las más perjudicadas, ya que en 2004 era la principal moneda de referencia con una participación del $45 \%$ del mercado, frente a un $25 \%$ que representa en 2019.

La multiplicidad de divisas de referencia de pago en los contratos de derivados puede ser un buen indicador que pone en la pista de las relaciones geoeconómicas entre grandes regiones mundiales (McCauley e Ito, 2018; Cheung, McCauley y Shu, 2019) . Los centros de gravedad financieros operan en un mayor número de monedas como consecuencia de una mayor influencia en diferentes territorios, y no necesariamente corresponde con su peso específico en el mercado global de derivados. Estados Unidos y Reino Unido encabezan la diversificación en divisas de operaciones de derivados, con contratos más de 30 monedas diferentes. En un segundo nivel, los mercados de Francia, Singapur y Hong Kong operan en rangos entre 20 y 30 divisas distintas. Todos los Estados tienen estructuras de conversión monetaria de sus contratos, que pueden expresarse en la moneda local del territorio y con las garantías legales del país donde se firma, o bien estar expresado en una moneda internacional. También existe la posibilidad en los contratos entre operadores financieros situados en dos Estados, de referenciar los pagos en una de las monedas locales, aunque con derechos de conversión a terceras monedas si así figura en el contrato. Esto permite limitar los riesgos de inestabilidad monetaria entre ambas partes, donde un episodio de inflación puntual del euro puede suponer un incremento automático de los derechos ligados a derivados cuya ejecución de contrato esté expresada en esta moneda. La posibilidad de reconversión a dólar evita así la exposición de este tipo de contratos, al mismo tiempo que hace más complejo el sistema de relación espacial en los intercambios monetarios. Para el caso de las permutas, Ferri-Ricchi (2013, p. 282) señala dos grandes corrientes que determinan relaciones espaciales opuestas entre los circuitos monetarios internacionales. En el modelo británico, el deudor del swap puede elegir la moneda de pago según el tipo de interés vigente durante el día de su vencimiento; sin embargo, si el día de pago se retrasa es el acreedor quién elige la moneda. En el modelo francés, se trata de un sistema de contrato más complejo entre dos operadores, que permite ejecutar el pago según el tipo y moneda de un día previamente asignado.

La elección de moneda de pago es un elemento crítico en la configuración de los contratos de derivados, que provoca incrementos sustanciales en la demanda global de divisas, provocando la necesidad por parte de los gestores financieros de deslocalizar los mercados de contratación y liquidación de divisas en las cámaras de compensación -clearing hubs- de numerosos espacios, tal y como ocurre por ejemplo con la comercialización del yuan offshore en los centros de Londres o Fráncfort. D’Avino (op cit. 2017) alerta de este fenómeno sobre el exceso de riesgo asumido por las oficinas extraterritoriales de los bancos globales. Determinados tipos de permutas permiten intercambiar en un futuro determinado un pago en dólares a interés fijo frente a un pago en euros a interés variable. El tipo de moneda y sistema de pago contratado induce a la descentralización de esta actividad en delegaciones localizadas en territorios de acuñación, con el objeto de disminuir los costes de intercambio de divisas. Asimismo, en EE.UU. la Ley Dodd-Frank promueve la diversificación geográfica de las permutas con el objetivo de rebajar el riesgo de una excesiva concentración financiera de este producto en el interior del país. A ello hay que añadir la existencia de lagunas entre legislaciones de distintos países, similares a las medidas de elusión fiscal utilizadas por empresas transnacionales-base erosion and profit shifting-, que facilitan la deslocalización de las operaciones con permutas. Los detalles técnicos en la liquidación vienen condicionados por la jurisdicción correspondiente, y una multiplicidad de centros extraterritoriales permite aprovechar brechas legales de operaciones que no podrían ser realizadas de otra forma.

Las permutas de tipo de interés o IRS son uno de los productos de contagio financiero más peligrosos, debido a las transacciones de capital que se generan entre las oficinas periféricas y su sede central, y es donde D'Avino (op cit. 2017) ha situado el origen del contagio financiero de la crisis entre países. Es lo que ocurrió por ejemplo en 2008 en el rescate bancario de EE. UU. al American International Group (AIG) como consecuencia de las operaciones de venta masiva de permutas en su sucursal de Londres, que se transmitió espacialmente a su sede central en Nueva York y provocó un rescate de 180000 millones de dólares por el gobierno federal. El contagio espacial se inicia en Londres, pero su rescate está financiado por EE. UU. Esto pone de manifiesto la aparición de situaciones 


\section{GRÁFICO 3}

PRINCIPALES DIVISAS UTILIZADAS EN LOS QUINCE MAYORES MERCADOS FINANCIEROS DE DERIVADOS

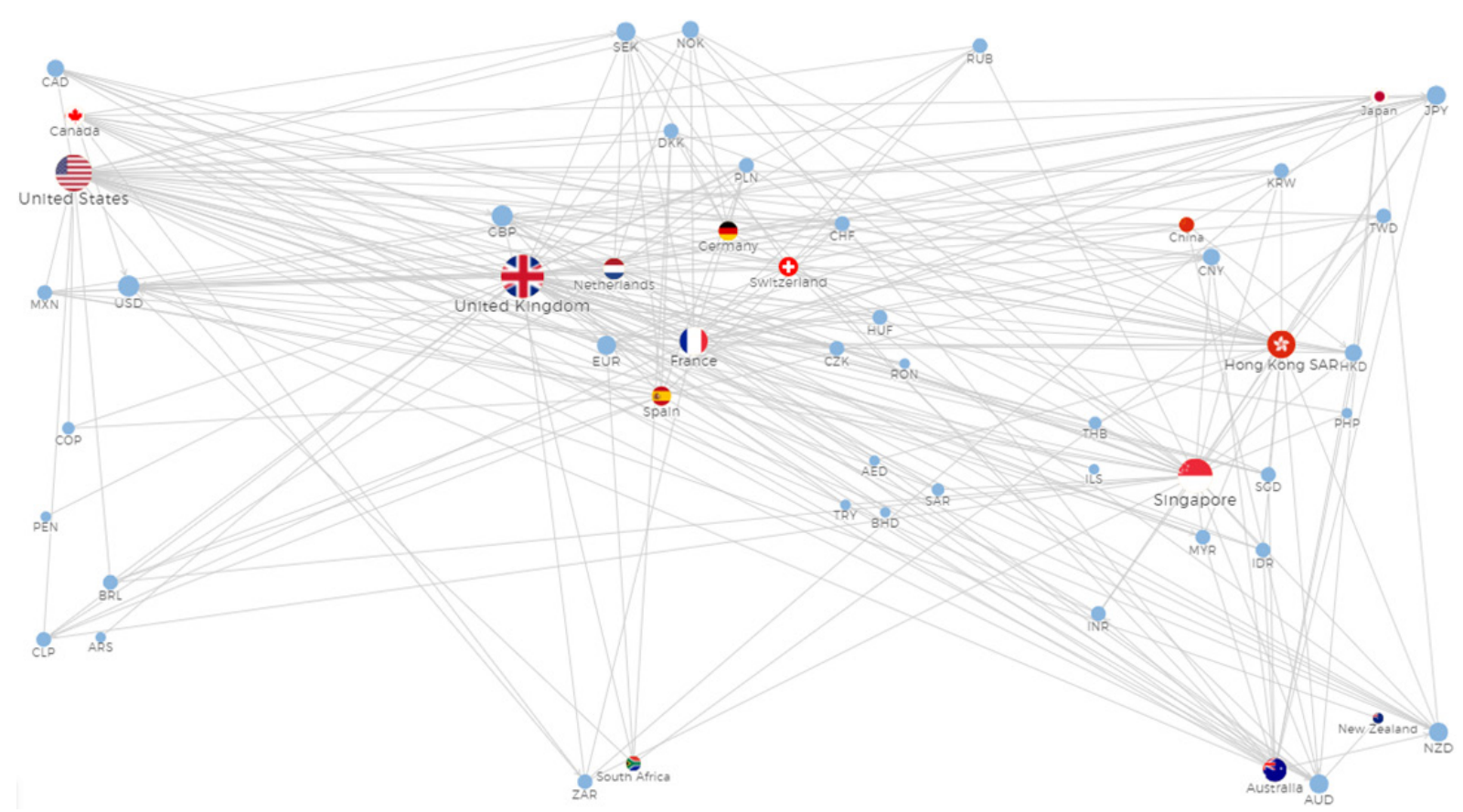

Fte.: BPI 2019 y elaboración propia. Los puntos con banderas corresponden a los centros financieros y los puntos en azul las divisas utilizadas.

socialmente injustas donde los ciudadanos de un país se ven obligados a hacer frente a las deudas de sus grandes corporaciones como consecuencia de operaciones irresponsables de alto riesgo diseñadas para obtener mayores beneficios en terceros territorios.

El gráfico 3 representa los movimientos de capital de los quince mayores mercados de intercambio y los flujos origen-destino que se relacionan entre divisas y sus centros internacionales de referencia. El del Reino Unido es el más diversificado del mundo, con operaciones declaradas en 2019 en 38 monedas diferentes de la libra. Opera con transacciones mensuales valoradas por valor de 3,6 billones de dólares, de las que solo un $15 \%$ están expresadas en esta moneda. El segundo mayor mercado OTC es el de EE. UU., que registra contratos por valor de 2,3 billones de dólares y en 33 divisas diferentes. Al contrario de lo que ocurre en Reino Unido, el 90,9\% de los flujos financieros están registrados en dólares.

Descender en la escala de análisis permite observar con mayor detalle algunos factores que forman parte de las tendencias de localización de la cartografía de flujos financieros. En primer lugar, destacan factores histórico-culturales. Estos facilitan la deslocalización de actividades financieras en aquellos espacios don- de siguen existiendo estrechos lazos, e intensifica las relaciones entre los centros financieros regionales y sus espacios de influencia. Es lo que ocurre por ejemplo con el mercado español de derivados, que opera con productos consignados en moneda de México, Colombia o Chile. La presencia de grandes bancos españoles en estos países facilita mayores interacciones financieras entre mercados, que incrementa el tráfico comercial, la movilidad de capital financiero y por supuesto las plusvalías entre Hispanoamérica y España. Por el contrario, multiplica exponencialmente la capacidad de contagio en caso de crisis, como consecuencia de una creciente interdependencia de los distintos nodos de la red, que se transmite como acelerador desde el sector financiero al resto sus economías.

En segundo lugar, la contigüidad espacial y un mayor conocimiento del territorio y sus condiciones geopolíticas siguen siendo un importantes factores explicativos en los procesos de diversificación espacial del mercado de derivados. Su situación interna o en su contexto internacional permite perfilar con mejor criterio el riesgo de deslocalización de inversiones financieras a terceros países. La estructura de los análisis de riesgo-país contemplan este tipo de factores a la hora de determinar los criterios de inversión en sus 
espacios de destino. La inestabilidad provocada por conflictos internacionales, cambio de régimen político o incertidumbre económica están detrás de la volatilidad de un mercado con escasas restricciones de movilidad y costes derivados de la desinversión, que aceleran aún más la inestabilidad de los mercados, tanto de origen como especialmente aquellos más vulnerables de destino.

Un tercer factor, viene determinado por la desigual capacidad de atracción espacial de los grandes centros financieros internacionales, que por su tamaño absorben operaciones en todo tipo de monedas y que constituyen un tipo diferente de relación entre territorios. La moneda declarada sobre la que se realizan los contratos de derivados es un indicador de los espacios geoeconómicos de influencia de sus centros de referencia.

La importancia de Reino Unido como nodo central que absorbe la mitad $(50,6 \%)$ de los movimientos mundiales del mercado de derivados, no se refleja en el peso de la libra como moneda de referencia, que representa un 7,9\% de la circulación de derivados. Ya se ha visto con anterioridad como el dólar es la moneda de referencia mundial, y solo el euro puede competir con garantías en los mercados internacionales. Entre ambas representan un $74,2 \%$ del valor de los contratos declarados, por lo que el resto de las monedas se reparten un mercado marginal. En este contexto llama la atención que las transacciones internacionales en dólar australiano, con un PIB similar a España, dupliquen al yen $(6,2 \%$ y $3,3 \%$ respectivamente), cuando los movimientos de derivados del mercado nipón (135000 millones diarios) superan con claridad a los del australiano (97000).

A pesar de los esfuerzos que China está haciendo en internacionalizar el renminbi como valor de referencia, su circulación apenas supone el 0,5\% de todas las transacciones de derivados, muy por debajo de su nivel económico, y por detrás de monedas de economías menos importantes como el dólar canadiense, el neozelandés o la corona sueca. No deja de ser significativo el mantenimiento del dólar hongkonés como moneda de referencia en su región administrativa, un factor que a priori dificulta aún más los intentos de externalizar el uso del renminbi en transacciones de la región Asia-Pacífico (Cheung, 2019). Tan solo 12700 de los 435800 millones de dólares diarios que circulan por Hong Kong en productos derivados se realizan en yuanes, lo que incrementa aún más el papel de esta región como nexo de intercambios con las principales economías de Europa y América.
Siguiendo los resultados del BPI (op cit. 2019), Reino Unido es con diferencia el mercado financiero mundial con mayor grado de diversificación espacial. Su función como eje geoeconómico de conexión entre la UE y EE. UU. facilita la diversificación de monedas en sus operaciones mundiales. Un tercio de ellas se realizan en dólares, frente a un $43,1 \%$ en euros y un $14,5 \%$ en libras. Dólar australiano, yen o corona sueca son también monedas de referencia que superan un $1 \%$ de sus operaciones.

Al contrario de lo que sucede en el caso británico, en Suiza se registra una menor presencia del euro en el balance global de operaciones (11,8\%), manteniendo al dólar como moneda de referencia $(50,6 \%)$, frente a un $20,1 \%$ de contratos en francos suizos. En el caso de la UE (sin Reino Unido), la diversificación geoeconómica es importante debido a la pluralidad de países y sus espacios de influencia. Un 15,9\% de sus contratos están referenciados en dólares, y apenas un $4,7 \%$ en libras esterlinas. Es significativa la asimetría en las relaciones financieras entre Reino Unido y la UE. Si la presencia de operaciones con empresas de la UE es habitual en Londres, es menos frecuente las operaciones en libras en los centros financieros de la UE continental.

Las relaciones espaciales dentro de la UE determinan a su vez subcentros de gravedad marcados por la interacción entre mercados financieros según su proximidad o influencia cultural. En el mercado financiero escandinavo, incluida Finlandia, es frecuente encontrar en sus contratos de derivados una cierta diversificación de contratos en corona sueca, noruega y danesa. Lo mismo ocurre con el eje Polonia-ChequiaAustria, donde al predominio del dólar y euro hay que añadir operaciones expresadas en corona, esloti o florín húngaro.

La red monetaria de los mercados de Europa Occidental se encuentra más diversificada que las anteriores regiones. La influencia cultural queda reflejada en la incidencia del peso mexicano en el mercado financiero español, con contratos declarados por valor de 4580 millones de dólares. Hay también en el mercado español derivados registrados en peso colombiano y chileno o real brasileño. La potencialidad de crecimiento del mercado de derivados español podría tal vez proceder del espacio latinoamericano.

Francia es con diferencia el mercado financiero de derivados más importante de la eurozona, con productos por valor de 120000 millones de dólares con presencia de contratos en mercados globales como Japón, 
Australia, Suecia y Noruega. Este contrasta con el caso germano, con productos declarados por valor de 56000 millones de dólares, menos de la mitad que el galo y con un menor nivel de diversificación monetaria.

Es significativo observar cómo un mercado financiero global como el de Luxemburgo solo declara derivados en dólar, libra y euro, cuando estamos viendo la multiplicidad de divisas en otros centros financieros. La especialización y creciente concentración de este producto le ha supuesto perder peso específico de manera sostenida desde 1995, ocupando en la actualidad una posición marginal.

En el espacio financiero americano, la diversificación de monedas es mucho menor al europeo debido a la clara influencia del dólar sobre las economías de todos el continente. El euro apenas representa un $3 \%$ de los derivados, inferior incluso a los contratos registrados en dólar canadiense. Ello no implica que la enorme dimensión del mercado estadounidense, el segundo mayor del mundo tras el británico en este producto, permita declarar derivados en 33 monedas de todo el mundo, donde al margen de la libra, y el euro destacan productos con moneda de Australia, México, Japón y Sudáfrica -el único país africano que ha declarado derivados al BPI-, aunque su peso relativo es residual en el conjunto global.

Si en Europa Reino Unido es el espacio con mayor diversificación espacial de operaciones financieras, en Asia este papel se reparte entre Hong Kong y Singapur. La RAE de Hong Kong es con diferencia el mayor mercado de derivados de toda Asia, con operaciones valoradas en 435000 millones de dólares. Sus operaciones en dólares solo suponen el $20,4 \%$ de su mercado, treinta puntos por debajo del promedio global. La presencia del euro en el mercado hongkonés es residual $(1,2 \%)$, y la absorción principal de derivados procede del dólar australiano, que supone el $61,7 \%$ del valor de sus contratos. Al igual que ocurre con Singapur, Nueva Zelanda también es un espacio de atracción geoeconómica del centro financiero de Hong Kong, con 21000 millones de dólares registrados.

En el caso de Singapur existe una acusada multiplicidad de monedas, con una estructura espacial de su mercado financiero alejada del triunvirato del dólar, que apenas supone un $20,6 \%$ de sus operaciones, y con una presencia testimonial del euro y la libra. Su eje de gravedad se dirige al mercado de Oceanía, con el dólar australiano $(31,9 \%)$ y el neozelandés $(6,7 \%)$ como principal referencia. Esto supone que su centro financiero es al menos en lo que respecta a los derivados, la puerta de conexión de Oceanía con los mercados financieros internacionales. Junto a esta funcionalidad global, Singapur es capaz de absorber operaciones de buena parte de la región del Pacífico, donde aparecen significativas operaciones en monedas regionales como el bath tailandés, el dólar hongkonés o el won coreano. Otras grandes potencias financieras regionales tienen un peso específico importante en Singapur, que se materializa en significativas operaciones en rupias o yenes.

En el caso de Japón, las operaciones de derivados tienen un componente local más acusado que en el resto de los grandes centros financieros mundiales. La influencia espacial de su mercado es completamente diferente, más autárquico y probablemente enfocado en contratos para cubrir las operaciones de su tejido empresarial. No es así de extrañar la limitada capacidad de internacionalización de su mercado de derivados, con excepción de una participación mínima del dólar australiano. Esto explicaría que el $88,10 \%$ de las operaciones se realizan en yenes, solo un $10,3 \%$ en dólares y la presencia del euro es irrelevante $(0,17 \%)$.

La capacidad de externalización de la red financiera de Sudamérica es prácticamente inexistente y sus mercados están diseñados en su totalidad para su economía interna. En el caso de Oriente Próximo es similar con la excepción de Emiratos Árabes Unidos, aunque con conexiones muy limitadas pero significativas desde el punto de vista geopolítico con Rusia, Sudáfrica, China o Tailandia.

\section{CONCLUSIONES}

Aunque el valor global del mercado de derivados no ha parado de crecer, las tendencias de movilidad de los flujos de capital parecen seguir los mismos parámetros de contracción espacial que se han detectado en otros movimientos financieros analizados en estudios anteriores, como son los casos de la Inversión Extranjera Directa o las emisiones de deuda soberana (op. cit. Fernández Cela, 2015, 2015b).

Con el dólar a la cabeza como moneda de referencia indiscutible, el eje de gravedad de las operaciones con derivados gira en torno a las divisas más estables de referencia internacional (euro y en menor medida libra esterlina). La proximidad geográfica entre operadores sigue siendo una constante en sus inversiones. Junto a ello, un buen conocimiento del mercado, una evaluación del riesgo-país y de su situación geopolítica, así como una cultura e idioma compartidos son aspectos claves en las decisiones de localización de los 
flujos y la estructura espacial de los territorios donde se negocian los contratos.

Determinadas técnicas de pastoreo influyen también en la decisión de localización en derivados. La concentración de estos productos en un reducido número de gestores especializados favorece este sistema, donde habitualmente las decisiones del propio gestor en torno a su red espacial de actividades financieras son seguidas de forma mayoritaria por buena parte de inversores en su cartera. Otros factores de localización destacados son la viabilidad de un marco jurídico garantista sujeto a determinadas condiciones de arbitraje, y una regulación flexible que permita operaciones especulativas no aprobadas en la normativa legal de Estados con mayores niveles de protección.

La deslocalización espacial de la cadena de derivados persigue identificar aquellos territorios con una estructura legal que garantice el cumplimiento de los términos del contrato con la contraparte. Estos movimientos hacia espacios con menor capacidad de regulación provocan una paradoja. Su dopaje financiero supone una enorme fuente de ingresos que provoca numerosas desigualdades sociales, al mismo tiempo serio que pone riesgo su estabilidad económica, por la ósmosis desigual entre una estructura nodal global y una red financiera local, que no está diseñada ni es capaz de soportar inversiones de alto riesgo de determinados flujos de capital. Los movimientos transnacionales desde centros globales a locales constituyen una fuente de inestabilidad económica, social y política en aquellos Estados más vulnerables a la volatilidad y comportamiento especulativo de los mercados.

La literatura sobre esta cuestión, no es aún suficiente para conocer con mayor detalle las relaciones de causalidad entre estructuras financieras societarias y redes espaciales comunes. Los indicadores revelan tendencias a construir espacios de soberanía financiera compartida cuando coexisten cultura, lengua, gestores y redes de información. La concurrencia de estas condiciones indica: primero, existen factores singulares que condicionan los movimientos espaciales de capital financiero; segundo, las redes financieras internacionales utilizan estas diferencias espaciales como estructura para la extracción de enormes plusvalías.

El papel que juega el territorio podría sintetizarse en diversos factores, entre los que se encuentran: diferencias jurisdiccionales; aprovechamiento ilícito de lagunas legales entre países; desigualdad de acceso al capital; condiciones dependientes de la calificación de riesgo-país; instituciones con limitada capacidad de regulación; incapacidad de ejercer una supervisión eficaz por reguladores locales; desviación de productos financieros de alto riesgo a espacios inmaduros; autoridad efectiva limitada y abusos de poder en el ejercicio diferencial de la soberanía nacional entre inversores residentes y no residentes.

Los resultados obtenidos sobre la estructura espacial del mercado de derivados avalan estas conclusiones. Reino Unido concentra el mercado de derivados extrabursátiles más grande del mundo. Justo al contrario de lo que ocurre en los mercados bursátiles, donde Estados Unidos, con Chicago a la cabeza, encabeza la jerarquía mundial. La centralidad de ambos espacios les permite diseñar una sofisticada y diversificada red espacial global, que se traduce en operaciones financieras conjuntas entre múltiples divisas. El resto de los centros financieros internacionales tienen una capacidad de atracción espacial más limitada en el mercado, ligada en buena parte a factores de proximidad geográfica, donde las divisas comúnmente utilizadas pertenecen a países relativamente próximos, o dentro de un claro espectro de influencia geoeconómica y geocultural.

La estructura organizativa de los grandes operadores financieros internacionales está detrás de los mecanismos de transmisión de riesgo entre países. Los tipos de interés que se suscriben a través de las filiales deslocalizadas en los grandes espacios financieros globales son parcialmente responsables del contagio. A ello hay que añadir la volatilidad de operaciones conjuntas sobre empresas sistémicas de los distintos países donde ejecutan operaciones especulativas, que ponen en riesgo la estabilidad del sistema financiero mundial. Sería interesante que investigaciones posteriores de casos permitan reconstruir la red espacial de los grandes fondos de inversión, un aspecto que considero crítico para comprender los factores de localización de los movimientos internacionales de capital.

\section{BIBLIOGRAFÍA}

Aalbers, M. B. (2015). Financial geography: introduction to the virtual issue. Transactions of the Institute of British Geographers, 40(2), 300-305. https://doi.org/10.1111/tran.12081

Aalbers, M. B. (2016). Corporate financialization. International Encyclopedia of Geography: People, the Earth, Environment and Technology: People, the Earth, Environment and Technology, 1-11. https:// doi.org/10.1002/9781118786352.wbieg0598

Abad, J., Aldasoro, I., Aymanns, C., D’Errico, M., Rousová, L., Hoffmann, P., yRoukny, T. (2016). Shedding 
light on dark markets: First insights from the new EU-wide OTC derivatives dataset (no11). ESRB Occasional Paper Series.

Agnes, P. (2000). The "end of geography" in financial services? Local embeddedness and territorialization in the interest rate swap industry. Economic geography, 76(4), 347-366. https://doi. org/10.1111/j.1944-8287.2000.tb00148.x

Algieri, B. (2018). A Journey Through the History of Commodity Derivatives Markets and the Political Economy of (De) Regulation. ZEF-Discussion Papers on Development Policy, (268). https://dx.doi. org/10.2139/ssrn.3301143

Barth, M. E., y Landsman, W. R. (2010). How did financial reporting contribute to the financial crisis? European accounting review, 19(3), 399-423. https://doi.org/10.1080/09638180.2010.498619

Bauer, R., Bonetti, M., y Broeders, D. (2018). Pension funds interconnections and herd behavior. Working Paper $\mathrm{n}$ 0 612. De Nederlandsche Bank. Recuperado de https://cris.maastrichtuniversity. nl/en/publications/70289833-cc7a-4bc3-8afc83adb399347a

Boddy, M. J. (1976). The structure of mortgage finance: building societies and the British social formation. Transactions of the institute of British Geographers, 58-71. https://doi.org/10.2307/621313

Bonizzi, B., yKaltenbrunner, A. (2019). Liability-driven investment and pension fund exposure to emerging markets: A Minskyan analysis. Environment and Planning A: Economy and Space, 51(2), 420-439.

BPI (2019). OTC interest rate derivatives turnover in April 2019. Triennial Central Bank Survey. Recuperado de https://www.bis.org/statistics/rpfx19_ ir.pdf

Cheung, Y. W., McCauley, R. N., y Shu, C. (2019). Geographic spread of currency trading: the renminbi and other EM currencies. BIS Working Papers n으 806. https://doi.org/10.1111/cwe.12292

Clark, G. L. (2006). Setting the agenda: the geography of global finance. In Economic Geography (pp. 105-115). Routledge. Recuperado de https:// ora.ox.ac.uk/objects/uuid:3d2d3e4c-9bbb-42a89c99-0535fa920c40

Clark, G. L. (2017). Financial intermediation, infrastructure investment and regional growth. Area Development and Policy, 2(3), 217-236. https:// doi.org/10.1080/23792949.2017.1345641
CNMV (2006). Estudio sobre los hedge funds. Servicio de Publicaciones de la Comisión Nacional del Mercado de Valores. Recuperado de https:// www.cnmv.es/DocPortal/Publicaciones/OTROS/ HedgeFunds_02_2006.pdf

Crotty, J. (2009). Structural causes of the global financial crisis: a critical assessment of the 'new financial architecture'. Cambridge Journal of Economics, 33(4), 563-580. https://doi.org/10.1093/cje/bep023

Daher, A. (2016). Externalidades territoriales de la gobernanza financiera global. EURE. Santiago de Chile, 42 (126), 213-236.

D’Avino, C. (2017). Banking regulation and the changing geography of off-balance sheet activities. Economics Letters, 157, 155-158. https://doi. org/10.1016/j.econlet.2017.05.035

Duffie, D., y Hu, H. T. (2008). Competing for a share of global derivatives markets: trends and policy choices for the United States. University of Texas Law, Law and Economic Research Paper, (145). https://dx.doi.org/10.2139/ssrn.1140869

Dymski, G. A. (2017). Making Financial Instability Visible in Space as Well as Time. Money and Finance After the Crisis: Critical Thinking for Uncertain Times, 91.Recuperado de

ESMA (2019). Directrices sobre el cálculo de posiciones por los registros de operaciones en virtud del Reglamento relativo a los derivados extrabursátiles, las entidades de contrapartida central y los registros de operaciones (EMIR). Recuperado de https://www.esma.europa.eu/sites/default/files/ library/esma70-151-1350_guidelines_on_position_calculation_by_trs_under_emir_es.pdf

Fernández Cela, J. C. (2015). Estructura espacial de los flujos de Inversión Exterior Directa en España. Primeros pasos para la elaboración de una cartografía financiera. Geopolítica (s), 6(1), 107136. http://dx.doi.org/10.5209/rev_GEOP.2015. v6.n1.47546

Fernández Cela, J. C. (2015b). Geografía de la deuda pública española. Algunas consideraciones espaciales desde la perspectiva política. Boletín de la Asociación de Geógrafos Españoles, (67). Recuperado de https://eprints.ucm.es/id/eprint/50955/

Fernández Cela, J. C. (2019). Estructura espacial de los centros financieros offshore en Europa. Boletín de la Asociación de Geógrafos Españoles, (80). http://orcid.org/0000-0001-6131-6103 
Ferri-Ricchi, A. (2013). El contrato de swap como tipo de derivado. Tesis doctoral. Universidad Complutense de Madrid. Recuperado de https://eprints. ucm.es/22814/1/T34726.pdf

Fichtner, J. (2016). The anatomy of the Cayman Islands offshore financial center: Anglo-America, Japan, and the role of hedge funds. Review of International Political Economy, 23(6), 10341063.3. https://doi.org/10.1080/09692290.2016 .1243143

Fisanotti, L. (2014). Antecedentes Históricos de los Mercados de Futuros y Opciones: Cobertura y Especulación. Invenio, 17(33), 9-19. Recuperado de https:// www.redalyc.org/pdf/877/87732404002.pdf

Fung, W., y Hsieh, D. (2004). Hedge Fund Benchmarks: A Risk Based Approach. Financial Analyst Journal 60:65-80. https://doi.org/10.2469/faj.v60. n5.2657

Gandré, P., Mariathasan, M., Merrouche, O., y Ongena, S. (2020). Unintended Consequences of the Global Derivatives Market Reform. Swiss Finance Institute Research Paper, (20-02). https://dx.doi. org/10.2139/ssrn.3518411

Harvey, D. (1974). Class-monopoly rent, finance capital and the urban revolution. Regional Studies, 8(3-4), 239-255. https://doi. org/10.1080/09595237400185251

Hobson, J. A. (1902). Estudio del imperialismo. Alianza Editorial, Madrid, 1981.

Houston, J. F., Lin, C., y Ma, Y. (2012). Regulatory arbitrage and international bank flows. The Journal of Finance, 67(5), 1845-1895. https://doi. org/10.1111/j.1540-6261.2012.01774.x

Huang, W., Meoli, M., yVismara, S. (2019). The geography of initial coin offerings. Small Business Economics, 1-26.

Kalinowski, M. (2011). Over-the-counter derivatives market in view of the global financial crisis 2007-2009. Economics y Management, 16, 11241129. Recuperado de https://www.academia. edu/1769728/OVER_THE_COUNTER_DERIVATIVES_MARKET_IN_VIEW_OF_THE_GLOBAL_FINANCIAL_CRISIS_2007_2009

Kellard, N., Millo, Y., Simon, J., y Engel, O. (2017). Close communications: hedge funds, brokers, and the emergence of herding. British Journal of Management, 28(1), 84-101. https://doi. org/10.1111/1467-8551.12158
Marjosola, H. (2019). The problem of regulatory arbitrage: A transaction cost economics perspective. Regulation \& Governance. https://doi. org/10.1111/rego.12287

Marquina, A. (2013). Los derivados financieros, su impacto en la seguridad alimentaria y los intentos de regulación. Revista UNISCI, (31), 149-170. Recuperado de http://www.redalyc.org/articulo. oa?id=76725704014

McCauley, R. N., y Ito, H. (2018). A key currency view of global imbalances. Journal of International Money and Finance, 94, 97-115. https://doi. org/10.1016/j.jimonfin.2019.01.013

Méndez Gutiérrez del Valle, R. (2019). La telaraña financiera: Una geografía de la financiarización y su crisis Barcelona. Ril Editores. https://doi. org/10.5565/rev/dag.586

Méndez Gutiérrez del Valle, R. (2020). Ciudades en venta: Estrategias financieras y nuevo ciclo inmobiliario en España (Vol. 21). Universitat de València.

Mihaljek, D., y Packer, F. (2010). Derivatives in emerging markets. BIS Quarterly Review, December. Recuperado de https://papers.ssrn.com/sol3/papers.cfm?abstract_id $=1727412$

Muellerleile, C. (2015). Speculative boundaries: Chicago and the regulatory history of US financial derivative markets. Environment and Planning A, 47(9), 1805-1823. https://doi. org/10.1068\%2Fa130343p

Nguyen, L. T., Sy, M. O., Cheng, M. Y., Hossain, S., y Chen, T. B. (2019). Are Funds of Hedge Funds Efficient? An Empirical Analysis for North American, Asia Pacific, and European Long/Short Funds of Hedge Funds. Multinational Finance Journal, 23(1-2), 37-64. Recuperado de https://econpapers.repec. org/scripts/redir.pf?u=http\%3A\%2F\%2Fwww. mfsociety.org\%2Fmodules\%2FmodDashboard\%2 FuploadFiles\%2Fjournals\%2FMJ 0 p 1dl1svd771 e2vl581j588Ipos4.pdf;h=repec:mfi:journl:v:23:y: 2019:i:1-2:p:37-64

Ontiveros, E. (2017). Introspección global. Vulnerabilidad europea al aislacionismo y a los nuevos proteccionismos. Geoeconomías del s. XXI. CESEDEM, 93-138. Recuperado de

Roe, M. J. (2010). The derivatives market's payment priorities as financial crisis accelerator. Stan. L. Rev., 63, 539. 
Satis Crypto (2018). Cryptoasset Market Coverage Initiation: Network Creation. Recuperado de

Schroeder, P. (2019). Big banks score win as U.S. regulator proposes easing post-crisis derivatives rules. Reuters Business News. Recuperado de https:// www.reuters.com/article/us-usa-banks-swapsidUSKBN1W2223

Skinner, F. S., y Townend, T. G. (2002). An empirical analysis of credit default swaps. International Review of Financial Analysis, 11(3), 297-309. https:// doi.org/10.1016/S1057-5219(02)00077-7

Sokol, M. (2013). Towards a 'newer'economic geography? Injecting finance and financialisation into economic geographies. Cambridge Journal of Regions, Economy and Society, 6(3), 501-515. https://doi.org/10.1093/cjres/rst022

Teo, M. (2009). The geography of hedge funds. The Review of Financial Studies, 22(9), 3531-3561.

Uría Menéndez (2019). Servicios de inversión, gestión de activos e infraestructura de mercados. Boletín de Regulación Financiera. Recuperado de https:// www.uria.com/documentos/circulares/1139/ documento/8894/Boletin_Octubre_2019. pdf?id=8894

Vilariño, A. (2018). Regulación financiera y riesgos sistémicos bajo la hegemonía del capital financiero. Recuperado de https://www.researchgate.net/publication/325313973_Regulacion_financiera_y_riesgos_sistemicos_bajo_la_ hegemonia_del_capital_financiero

Wójcik, D., MacDonald-Korth, D., yZhao, S. X. (2017). The political-economic geography of foreign exchange trading. Journal of Economic Geography, 17(2), 267-286.

Zhang, H., y Kim, H. (2019). Foreign Bias of Sovereign Wealth Fund And Spatial Spillover Effects. The Singapore Economic Review, 64(02), 377-397. https://doi.org/10.1142/S021759081747004X

Z/yen (2019). Global Financial Centres Index. Recuperado de

\section{NOTAS}

${ }^{1}$ EL BBVA los define como "mercados extrabursátiles donde se negocian distintos instrumentos financieros (bonos, acciones, swaps, divisas...) directamente entre dos partes. Para ello se utilizan los contratos OTC, en los que las partes acuerdan la forma de liquidación de un instrumento".
${ }^{2}$ El IRS corresponde al tipo medio de interés de las operaciones de swaps a cinco años.

${ }^{3}$ Los expertos han pedido anonimato. Se puede ampliar la relación entre regulación y costes de transacción en Marjosola (2019).

${ }^{4}$ El cálculo del riesgo se basa en la aplicación del modelos estocásticos como el de Black-Scholes. Para ampliar esta cuestión se puede consultar a Vilariño (2018).

${ }^{5}$ Se trata de un conjunto de siete elementos que definen las condiciones de competitividad de los fondos de cobertura en los mercados financieros internacionales (Fung y Hsieh, 2004). Para ampliar la información de su comportamiento por tipo de fondos y regiones se puede consultar a Nguyen et al. (2019).

${ }^{6}$ Esta tendencia se mide a través de las operaciones transfronterizas de las mayores entidades financieras mundiales -reporting dealers-, que suministran información al BPI sobre su cartera de operaciones en su país de origen y en el exterior.

7 Cuando se habla de dólar en forma genérica se refiere a la moneda de Estados Unidos. Si se trata de la moneda de otros países se usa siempre su gentilicio correspondiente. 